\title{
Hong Kong MEP Review
}

\author{
Tianmeng Mao \\ (Business School, Zhengzhou University, Zhengzhou 450001, China)
}

\begin{abstract}
After participating in HK Management Enhance Program, the first-hand experiences are introduced, which include experiencing the professional working environment as well as the corporate culture in the world top financial company in the areas of finance, consultation, marketing and human resources etc.
\end{abstract}

Keywords: MEP, Finance, Marketing, Dialogue in the dark, Experience

\section{Introduction}

Management Enhance Program is planned and sponsored by IEEC and EDUA. By working in the world top finance corporation, experiencing the professional business competition, attending the world-famous human resources training course, students can develop their potentials, enrich the experiences, broaden the horizon and built a strong network connection to get improvement in the full range on a diversified platform.

It make great sense to participate in the MEP2013 Hong Kong internship which includes the students from the whole province majoring in different fields such as finance, accountant, human resources, and employs the staff from the World's Top Five Hundred Enterprises ${ }^{[1]}$, Prudential- Hong Kong. MEP provides every participant a great eight-day-program, which trains the students' skills in full aspects and ensures you a great improvement in both the major study and life.

\section{International Financial Enterprise Internship}

\section{$1^{\text {st }}$ Day (7-16-2013, Tuesday)}

We gathered at the port of Luohu in Shenzhen, after which we'll heading Regal Oriental Hotel by East Rail Line. After settle down, we are going to the practice base located in Tsim Sha Tsui Harbour City, in which we will experience working in the headquarters of Prudential, which is one of the world's top 500 companies. During the practice, we'll experience the environment and the culture of the company and participate in the training course for the course of money management. We'll also have a simulation of the investment. All students will be grouped and for each group we'll arrange a senior expert of the company as a guide.

The experience about economy will be all way through the practice, which will help us early set a clear goal about our career in the future by feeling this world top company and communicate with its employees, experiencing the atmosphere of the international company and its working environment.

\section{Public welfare marketing competition}

Public welfare marketing competition is one of the core parts of MEP program. The Prudential assigned the task by the time it had made a rough training for every group taking part. After receiving the training in management and marketing, the participators will get rid of the fetters of control by textbooks, instead, they are able to use the knowledge gaining at school to meet the practical needs in a real commercial environment. Having been given the start-up capital, each group is asked for producing a new product and sells it. To finishing the task, the group members need to do the market survey to know the demand, find the target consumer, do appearance design, fix the price and make marketing strategy ${ }^{[2][3]}$. Hong Kong Charity Foundation is focusing on the whole process. All the profit shall be donated to the foundation in the name of the group which can also be awarded the certification of international voluntary working.

20:00, intern began. Internship students were divided into three groups and each group had nine people, I was in group B. In the first two days, we were asked to complete a public marketing race. The content is to design and produce a product for Guizhou mountainous pupils aging from 6 to 9 years. The best products will be selected for mass production after the sale. Each group has \$ 200 (In this paper, \$ is HK\$) start-up funding. Product innovation, raw materials purchasing, product production, advertising should be completed by own team members. On the 18th at 3:30 pm 5:00 at Tsim Sha Tsui, we gave out questionnaires for product market survey to passers-by to access our products and asked for advice. 7:00 pm, the product launch meeting was held in the company.

When it came to discuss, the phenomenon was really active and harmonious. We first geo-location analyzed Guizhou and drew some conclusion about the climate, altitude, terrain and so on. Moreover, the target consumers are pupils who go to school several hours on the dark muddy slippery and bumpy mountain road from dawn to dusk. The mountain climate in winter is easy to frostbite. After discussing for two hours, the initial formation of the general idea is a raincoat, a pair of gloves, in order to face with the cold and rainy mountains of Guizhou hostile natural environment.

At 2:00, the ultimate scheme finally came out. The product called "love-warming two-piece" consists with a 
multifunctional raincoat and a pair of gloves as shown in Fig.1.

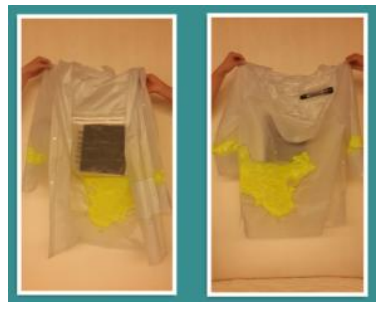

(a) Multifunction Raincoat

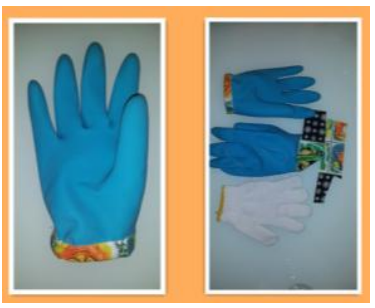

(b) Multifunction Gloves
Fig1: love-warming two-piece

\section{- Love Raincoat}

1) Combining the raincoat with schoolbag: a waterproof bag with zipper is inlaid in the raincoat, which is specially designed for the mountain area pupils in Guizhou Province according to the real condition.

2) Special fluorescent material: a China map painted with fluorescent paint is on the back of the raincoat, which makes the user can be seen in the dark and serves as a security alert. Not only does the special design show great respect for our nation, it also reflects back the nationwide concern.

3) Raincoat hat mounts miniature flashlight which can illuminate the dark mountain road in the morning and at night when walking. This can increase the safety rate.

4) On the back of the raincoat, we designed venting hole, which can enhance the comfort.

Materials: Plastic raincoat, plastic, harmless fluorescent paint, tiny flashlight, battery.

- Warming Gloves

1) Palm is designed with texture to avoid slipping.

2) warm keeping: Using internal and external two-tier structure, cotton gloves inside and external windproof rubber materials can double the ability of keeping warm.

3) waterproof

Materials: household kitchen gloves, mat, cotton gloves, needles and thread, scissors and so on.

Given to the background of the public service market race and mountain area pupils, we named our group as LED, which consisted of the first letters of the word "love", "education" and "dream". The special name, on one hand, is same as the abbreviation of light-emitting diode, which means the desire for illustrating the future road for the children.

$2^{\text {nd }}$ Day (7-17-2013, Wednesday)

On the 17th morning 8:00, we started purchase the raw materials and at 10:00 we began to product. Since 14:00 we need to arrive at the company at Causeway Bay to meet the mentor, we had to finish our task in advance.

All the work has been done by 3:00, everyone return to the hotel, tired but full of sense of accomplishment. We decided to rehearse for the production promotion 7:00 am in the hotel lobby.

\section{$3^{\text {rd }}$ Day (7-18-2013 Tuesday)}

We nine appeared on time in the hotel lobby at and the rehearsal was successfully completed. The scheduled visit to the Hong Kong Exchanges and Clearing Limited enabled us to better understand the history of Hong Kong financial development. After the visit, we got dressed in our team shirts and rushed to Star Ferry at Tsim Sha Tsui. 10 copies each person, we had a total of 90 copies of questionnaire to issue and was only allowed to survey in an allocated area.

The majority of our respondents were people who stopped by, students in dessert shops and foreign tourists. The first respondent was a woman around her 30s who stopped in front of a convenience store with her suitcase. Psychologically well prepared for wariness and suspicion people may have, I was just overjoyed and enthused that I was an intern student from a mainland university working for a non-profit project. When I spoke out "non-profit", she turned relaxed and readily agreed to join in the survey. After a brief talk, I waved goodbye to her, warmed inside. The success of the first try greatly encouraged my confidence. Considering that the users of the product are primary school students, I also made some survey on several young pupils and their parents.

When the survey finished, apparently I felt that foreigners were much more attentive than Chinese. They listened to my introduction with questions, and thought over every question on the sheet. Foreigners even wrote on the suggestion column, which was often neglected by Chinese. I was deeply inspired by their concerns about rights. It seems that westerners tend to grab every opportunity to express their point of view.

Most of the respondents have listened to my introduction enthusiastically and filled out the questionnaire carefully. However, there were many people who refused me with "sorry". Every time when I was refused I would immediately go on for the next person with the same enthusiasm.

Standing by the Tianxing dock, I felt the Hong Kong is such a free trade port, which has witnessed too much differences and conflicts, bringing about too much tolerance and integration. The huge differences make Hong Kong an international city, which also lead to the unique social formation with combination of the east and the west as well as cultural charm.

7:00 pm, we arrived at Prudential to attend the production promotion competition. Every minute of our presentation has been carefully designed. In the session of products show, I acted as a product model. The speaker introduced our products. Our performance proved to be outstanding, which won the praise of Prudential's staffs. Group A designed a table game with beautiful Disney checkerboard background which made the group proud of. But the company executives, Michael, had pointed out sharply: "You don't have Disney designs copyright." The moment, all of us was shocked. This business sensation is what we college students lack of. Group C made a versatile glass but not competitive. Eventually we Group B won the marketing champion. 


\section{Analysis and Practice of Investment Wealth Management}

Another core part of MEP program is investment and finance case study which is based on clients' demand. It devotes to designing a professional commercial case analytical plan book in full aspects by collecting clients' information and numerous real cases as well as the communicating skills and commercial speech delivery.

The $4^{\text {th }}$ to $6^{\text {th }}$ days (7-19 21-2013, Friday to Sunday)

We were given a resume of the client Richard and supposed to come up with a money managing plan through the study of relevant knowledge and practice.

The client basic information is as follows:

Richard works for three years after graduation with annual salary of $\$ 180000$, growth rate of $5 \%$, and annual bonus of $15 \%$. MPF (fund) he has to submit accounts for $5 \%$ of annual salary, with $\$ 3000$ per month going to his parents, credit card debt of $\$ 50000$, and the monthly payments for bank equaling the minimum quota of the requirements. $90 \%$ of the assets are utilized to invest in the stock market with $40 \%$ return in 3 years. Richard's father aged 55 years old and works for a large oil company, who will retire at the age of 60 . Richard's mother aged 53, works temporarily for a hotel, and plans to retire when Richard gets economic independence. His girlfriend Mary is a property company staff ,consenting to get married when a house is get ready; Richard wants to gain economic independence at the age of 50, whose personal hobby is computer games, irregularly taking exercise or participating in social activities.

\subsection{Overview and analysis of financial condition}

\section{(1) Overview}

\section{- Personal Income}

Richard, 25, has been working for a company for 3 years, being given an annual salary of $\$ 180,000$. The rate of salary growth is $5 \%$. Due to the value of the salary will be approximately offsetted against current local inflation; therefore, there is no need to account for the wage growth and inflation to calculate personal assets. The monetary unit of not indicated in the following formula are in $\mathrm{HK} \$$.

1)Working income: $180000 * 3+180000 * 15 \% * 3=621000$

2)Investment income: $316800 * 90 \% * 140 \%=399168^{[*]}$

- Supporting Parents Expenses

Richard has to support their parents for $\$ 3000$ per month (present value). Considering macroeconomic factors such as inflation causing currency depreciation, combined with his parents' physical condition and the factors of family reasonable anticipation, the support payment ought to be:

$$
3,000 * 12 * 23 *(1+3.9 \%)^{23} \approx 1,996,125.90
$$

- Marriage and House Expenses

Richard's girlfriend Mary is an office clerk with annual income $\$ 96000$. She holds the view that real estate is the basic factor of marry to Richard.

1) real estate: according to the per capita housing area of Hong Kong and Richard's current economic situation, we believe that the building area should be around $92 \sim 98$ $\mathrm{m}$ squared, and average price of $\$ 35000$ is more suitable . Required funds should be around $\$ 3000000$, decorate of about $\$ 200000$, attorney fees shall not exceed $\$ 100000$, which is:

$$
3,000,000 * 10 \%+200,000+100,000=700,000
$$

2) Wedding $\$ 200,000 \sim 300,000$

- Retirement and Pension Insurance $e^{[* * *}$

According to Hong Kong in 2012 per consumption ability data, the average monthly cost at $\$ 4700 \sim 5200$ level is conservative. With the Prudential Corporation pension formula, we get the following results:

Forecast annual expenditure on retirement (future value): $\$ 624,597$

Required pension (present value): \$14,230,033

Predictive value of savings: $\$ 1,013,018$

Still saving money (present value): $\$ 13,217,016$

The additional monthly savings: $\$ 4,025$

- future investment quota

$15,000+2,250-4,700-3,000-750-4,815=3,985^{[* * *]}$

Instructions: on matters related to the above calculation

[*]Securities investment funds

A. Necessary living expenses: $4,700 * 12 * 3=169,200$

B. Supporting parents expenses: $3,000 * 12 * 3=108,000$

C. MPF: $180,000 * 5 \% * 3=27,000$

Total expenditure: $\mathrm{A}+\mathrm{B}+\mathrm{C}=304,200$

Therefore, the asset which can be put into the stock market: $621,000-304,200=316,800$

$[* *]$ In accordance with the inflation rate of $3.9 \%$, expect the retirement age of 50 years.

[***]Per year reward apportion: $27,000 / 12=2250$

MPF apportion: $(180,000 * 5 \%) / 12=750$

Apportion to the real estate per month is:

$3,000,000 * 90 \% / 12 *(1+2.15 \%) * 50 \%=4,815$

(2) Analysis

According to the above personal financial data, there are lots of problems for Richard's investment strategy yet great potential to mining.

1) The portfolio too monotonous, risk aversion ability not strong enough

As a high-risk stocks occupying the main part of the personal financial management system, which can cause the instability of the personal financial system and is about to shoulder the huge potential risks.

2) Insurance products limited, asset preservation ability s insufficient

The property insurance product guarantee ability is not able to undertake risk in the investment structure, which is difficult to deal with emergency in a long period of time. Personal assets preservation ability needs to be improved deadly.

3) Income stable and reliable, and with huge potential in financial investment

\subsection{Invest Strategy and Wealth Managing Plan}

A reasonable investment strategy is like a pyramid. First layer is for the six months' salary; the second floor is for the insurance; the third layer possesses savings on the basis of insurance; the fourth floor is the funds or 
securities; fifth floor investment is for high-risk \& high-return stock or derivative products, etc ${ }^{[4][5]}$.

And Richard's financial investment emphasizes most in stocks, which is like the upside down triangle. The "top-heavy" structure has great hidden trouble. Stock is doomed to boom collapsed, and if Richard's stock fell seriously during a certain period of time, it will directly influence the total assets. What we suggest is to transfer out some funds from stocks, using the average cost method to do other investment so as to spread the risk.

According to Richard future investment quota of $\$ 3985$ per month, we recommend the Prudential Corporation's products, tailored for him a financial investment strategy: "Yunchou Rewarding + Wealth managing insurance" plan.

(1) Yunchou Rewarding Plan

The total investment is $\$ 800 \sim 1000$ per month. Invests following with average cost method to decrease the negative impact caused by fluctuation. The unique benefits are as follows.

1) Invests global markets when the cost just under $\$ 1000$ per month;

2) Abundant reward to the clients, which shall make the capital increment;

3) The tights to delay the fee of insurance, which makes the investment more flexible.

The reward of investment consists of first year reward, investing reward and long-period client reward and the reward will be allocated per year, per 5 year and at the end of the period respectively. The highest rewarding rate reaches to $16 \%$.

(2) Wealth managing insurance

Wealth managing pyramid has already illustrates the importance of insurance when managing wealth. A series of wealth managing insurance plan called 'fine plan' is raised up according to Richard's condition. The total investment is $\$ 942.73$ per month.

1) Term insurance

Features: premiums remain unchanged in the contribution period; Term insurance series is a pure life insurance with no dividends; $\$ 439$ in insurance premiums is enough. When misfortune occurs, the family will receive $2300000 \mathrm{HKD}$ in compensation, whose later life will have safeguard.

2) Super preferential plan for accident insurance

Partial and temporary disability in full, can obtain the compensation of 1000 and 4000 \$ per week. When meet the certain conditions, one will get double compensation, such as accident when a walk on a fixed route public transportation accident, or in the event of a fire in public building (such as hotels, schools) accident, etc.

In short, the plan for Richard in the total investment is about $\$ 1742.73$ per month, and $\$ 2242.27$ savings can be used for stock investment or savings. The investment ratio is in line with the financial pyramid structure.

\section{Dialogue in the Dark}

During the whole project, participants will not only serve as members in group, but they will also show themselves individually and enhance their own skills. It can improve you to a large extent in the field of communicating with team members, dealing with the company staff, leading the team to create brilliant and public speech addressing.

The $7^{\text {th }}$ day (7-22-2013 Monday)

In the morning, the whole team went to Dialogue in the Dark with the leader to take part in the highlight part of MEP program. Dialogue in the Dark, which located in the Nob Hill, Lai Chi Kok, Kowloon, is a venue with the theme of experiencing the blind life in Hong Kong. After a brief introduction, we were divided into several groups and stepped into the 75mins' dark world with a cane in hand. The guide took us to 5 different scenes to undergo the situation blind people faced with. We toured the park, went across the bustling streets, the market, cafes and ferries. Under the guidance of the skilled guide, participants' desire for communication had been roused. With the tacit cooperation, we took care of each other and completed this fancy tour successfully.

It's an impressive experience which not only make us have a new apperception of teamwork, but also learn the importance of touch and auditory sense to the blind and the hardship of them ${ }^{[6]}$. When we truly live and think from the perspective of blind people, we can learn a lot although we almost cannot see anything.

Through this internship, the participants have witnessed the employees' high-intensity work pace in the world leading financial firm. And they can see the unique charm of Hong Kong as one of the four biggest world-class financial centers. In the meantime, the financial community in Chinese Mainland is gradually opening up. Its huge financial markets and investment opportunities attract international financial institutions. Therefore, grasping the investment management skills has been the common pursuit of increasing number of Chinese youngsters. It is widely acknowledged that the international investment vision and comprehensive practical skills will make the new generation create bright world in the near future.

\section{References}

[1] Sun Xibao. Fortune issue the World's Top Five Hundred Enterprises in 2013[N]. Worker's Daily, 2013.7.10

[2] Shi Yue. Public welfare marketing: common intersection in varied areas[N]. China Enterprise News. 2010.8.16

[3] $\mathrm{Mu} \mathrm{Ke}$. Innovative public marketing pattern[N]. China Enterprise News. 2010.2.26

[4] Xu Sheng. Status quo analysis of Chinese personal finance[D]. Fudan University, 2010

[5] Yao Qiang. Research on Current Situations and Countermeasures of Asset Allocation of China's Wealth 
Management[D]. Southwestern University of Finance

Economics, 2011

[6] Tang Lin. Experience and Gnosis of "Dialogue in the Dark" In Ngee Ann Polytechnic[J]. Journal of Yangtze

University (Nat Sci Edit). 2013(12): 107-108 